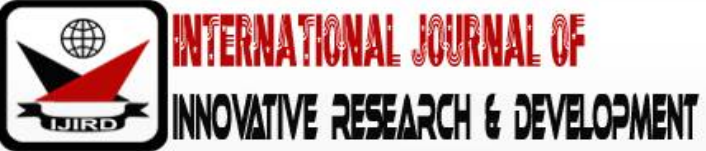

ISSN 2278 - 0211 (Online)

\section{Psychosocial Challenges of Caring For the Elderly: A Study of Family Caregivers in Enugu Urban, Southeastern Nigeria}

Ngozi Idemili Aronu
Lecturer, Department of Sociology/Anthropology, University of Nigeria, Nsukka, Nigeria
Nneka Umego
Lecturer, Department of Sociology/Anthropology, University of Nigeria, Nsukka, Nigeria
Ngozi Chukwu
Lecturer, Department of Social Work University of Nigeria, Nsukka, Nigeria
Chukwudi Christopher Nwokolo
Lecturer, Entrepreneurship and Development Research, University of Nigeria, Nsukka, Nigeria

\section{Abstract:}

Aging is often accompanied by chronic illness and continuous deterioration of mental and physical independence. This makes care giving necessary, complex and challenging. The objective of the study was to identify those social, economic and psychological changes facing family caregivers. The objective of this study was to identify those social, economic and psychological challenges facing family care givers in Enugu urban. A cross sectional survey was conducted in three LGAs in Enugu State. Using both qualitative and quantitative methods of enquiry, a total of 372 purposively selected respondents were interviewed using a structured questionnaire and an in-depth interview guide (IDI). The quantitative data was analyzed using and presented using percentages and descriptive analysis. The qualitative data was thematically analyzed. Results showed that majority (66.18\%) of the caregivers were females. Caregiving of the elderly is associated with social, psychological and economic challenges therefore inclusive social policies, economic incentives and psychosocial support is strongly recommended.

Keywords: Elderly, family caregivers, challenges, Nigeria

\section{Introduction}

In most societies, age is one of the bases for the ascription of status and also one of the underlying dimensions by which social interaction is regulated. Ageing comes to all in due time, if we live long enough. Ageing is often accompanied by chronic illnesses and continuous deterioration of mental and physical independence, which makes care-giving more complex and challenging (Davis, Gillis \& Harper, 2011; Ebimgbo, Chukwu, Onalu \& Okoye, 2019). People do not cope successfully with ageing all on their own, especially when they are suffering a chronic ailment. Most often they will cope in the company of others who provide social, emotional and financial support and assistance in surroundings that provides security, love and understanding (Connidis, 2010). This gives rise to the need for company or in general terms, a caregiver. In this respect, families of older people usually provide many forms of caregiving assistance for older people. Caregiving assistance in the context of this study is taken to mean all forms of support and assistance given to an elderly person. This could be by way of telephone calls, visits, financial support and physically caring for the person. Caregivers are often responsible for specialized medical care, planning and coordinating care, monitoring patient's health status, ensuring treatment or medication adherence and preventing adverse events (Okoye, 2012). Caregivers may also adopt the role of decision-maker, particularly if the care recipient is experiencing cognitive impairments.

In Nigeria, the general population is growing rapidly and is approaching 180 million. The United Nations predicts that the percentage of the Nigerian population aged 60years and above will increase by 26 percent by 2020 and 38 percent by 2050 (United Nations, 2015) thus making the need for elderly care a societal necessity. Notwithstanding the fact that there exist two classes of caregivers; commercial (formal) and family (informal) caregivers, the predominant group of caregivers found in Nigeria are mostly informal/family care givers. It is worth noting that the informal caregiver, beyond being a family member, could be a friend, neighbor or volunteer without specific training, often unpaid, caring for the elderly side-by-side with the family. Furthermore, in the traditional Nigerian society, the care and support of elderly persons are provided by the family members, especially the wives, sons, daughters, sons-in-law, and daughters-in-law (Ogwumike \& Aboderin, 2005). In some instances, the responsibility of caregiving is not simply taken on because of emotional bonds of relationship emerging out of blood relationship or marital relationship but by the force of pervasive influence of traditional values, norms, and behavior which were not simply practiced as a matter of routine but also deified (Okoye, 2012). 
Family caregiving is a common phenomenon in sub-Saharan Africa where the younger spouse, (often the wife) children or grandchildren have the obligation of caring for their older family members (McDaniel \& Pisani, 2012). These family caregivers are expected to assist their older relatives with performing activities of daily living and preventing falls and elder abuse (Help Age International, 2001; World Health Organization [WHO], 2011; Blake, 2017). More generally, they play a role in the physical, emotional, psychosocial and sometimes financial assistance of older family relatives who cannot care for themselves (National Alliance for Caregiving, 2010). It is without an atom of doubt that we can conclusively claim that the task of taking care of the elderly is not an easy one as it has severe physical, physiological and psychological impact on the caregiver. These effects are in most cases negative and always lead to deterioration in the physical state of the care-giver. The American Psychological Association [APA] identified some of the challenges faced by family care givers in taking care of the elderly. These challenges are sometimes summarized and tagged care-giver stress. These challenges were classified under mental health concerns (Depression, anxiety, sub-clinical stress, high rates of negative affect including guilt, sadness, dread, worry); Health concerns (Fatigue, sleep problems, risk of illness, injury, mortality). Others include; financial strains, loss of time for self-care and reduced quality of life (APA, 2014).

Though informal caregiving is often inherently rewarding for those who provide it, it can also be emotionally, physically, and financially burdensome (Chorn-Dunham \& Dietz, 2003; Ebimgbo, Chukwu, Onalu \& Okoye, 2019). Few people are prepared for the responsibilities and tasks involved in caring for the aged because of the stress involved in it. Furthermore, literature suggests that caregiving produces great amounts of caregiver burden and stress (Gupta, Rowe \&Pillai, 2009). Caregivers are at a greater health risk than the care receivers because when the caregivers devote themselves to the needs of someone else, they tend to neglect their own needs. They may not recognize or may ignore the signs of illness, exhaustion or depression that they are experiencing. Concurring to this, Friedland and Lewis (2004) stated that the physical, emotional and social burdens attached to providing care to a frail elderly person can exact a heavy toll on family caregivers, including loss of leisure time, increased stress and impaired physical and psychological health. Also, caregiving imposes considerable direct financial costs on caregivers and their families such as medical services, medical devices, drugs, food, clothing, and personal items for the elderly. Many caregivers in the workforce have to deal with such issues as lost wages, job security, career paths and employment benefits such as health insurance and retirement savings and so on (Chorn-Dunham and Dietz, 2003).

In many African countries and Nigeria in particular, caregiving of the elderly is culturally dictated and is therefore predominantly filial. Often psychological, emotional, social and economic needs of family caregivers are not adequately taking care of, making it a herculean task for caregivers. Thus, it is against this backdrop that this study sought to identify the challenges facing family caregivers of the elderly in Enugu urban, Southeastern Nigeria, with a view to proffering possible solutions to tackling these challenges.

\section{Conceptual Framework}

This study was hinged on the constructs of the attachment theory. Attachment theory was first developed to explain why infants become attached to their caregivers and emotionally distressed when separated from them. Drawing from principles of evolutionary theory, Bowlby (1982) argued that attachment behaviors in infancy are regulated by an innate behavioral system that functions to promote safety and survival by maintaining a child's proximity to a nurturing caretaker. Thus, when a child is frightened, ill, or in unfamiliar surroundings, the attachment system will be activated, and the child will seek protection and comfort from an attachment figure (Bowlby, 1982; Bretherton, 1985).

Although Bowlby focused primarily on infants and young children, he acknowledged the importance of studying attachment processes in adulthood and argued that the basic functions of the attachment system continue to operate across the life span and thus, the regulation and management of our emotional bonds with those closest to us is governed by the attachment behavioral system.(Bowlby, 1988). This integrated behavioral system motivates aged people to seek proximity to their attachment figures in order to gain comfort and a sense of safety when they feel threatened or distressed. Attachment theory, therefore, is not merely a theory of human bonding; it is a theory of emotional and distress regulation (Mikulincer \& Shaver, 2007a; Simpson \& Rholes, 1994). As such, the theory provides a comprehensive framework for understanding how close relationships shape the way in which families deal with stressors and strains, such as the emotional highs and lows of caring for an aging parent. Attachment theory provides a diathesis-stress approach for understanding how and why certain family members who encounter the stress of caring for an older adult tend to experience greater difficulty in the care-giving role.

\section{Materials and Methods}

\subsection{Study Area}

The study was a cross-sectional survey study conducted in three Local Government Areas [LGAs] in Enugu urban (Enugu North, Enugu South and Enugu East) in Enugu State, Southeastern Nigeria. According to the National Population Commission [NPC], 2006, Enugu state has a population of 3,267,837 and a total of 717,291 for Enugu urban. Enugu state covers 7161 square kilometers and is located between latitude $6{ }^{0} 30^{\prime} \mathrm{N}$ and longitude $7^{\circ} \mathbf{3} 30^{\prime} \mathrm{E}$. Enugu state is noted for its coal deposits hence is nicknamed the 'coal city' and the major language spoken is Igbo. Economically, Enugu state is predominantly rural and agrarian with a substantial proportion of its working population engaged in farming, trading and services. Enugu state has a total of 508 State owned and 349 private owned healthcare facilities that satisfy both primary and secondary healthcare needs and also two elderly care facilities. Enugu urban is made up of three LGAs and the study covered the three LGAs. 


\subsection{Sample and Sampling Procedure}

The target population for this study in Enugu urban is 449,947 and consisted of adults (male and female) within the age of 18-55yrs.The sample size for the quantitative study was 360, with a sample size of 120 assigned to each LGA. Purposive technique and snowballing were adopted to select the initialdwelling units and respondents that were caring for an elderly person. The initial respondents enlisted for this study helped link the researchers to other potential respondents. Twelve respondents (four from each LGA) were also sampled for the qualitative part of this study, making a total sample size of 372 . This study was conducted between the months of July-September, 2018

\subsection{Instruments and Data Collection}

Both quantitative and qualitative methods of enquiry were employed in this study. The instruments for data collection in this study were a structured questionnaire and In-depth interview guide[IDI]. The structured questionnaire was used to solicit information on respondents Socio demographic, social, economic and psychological challenges they face while caring for the elderly. The questionnaire was other administered by the researcher and four research assistants who were duly trained on the objectives of the study. The IDI guide was used to solicit in-depth information from family caregivers on their experiences and challenges they face while caring for the elderly. Data editing and validation was done on a daily basis. This was aimed at ensuring that problems were detected as early as possible when it was still possible to apply corrective measures. Data entry was done by the lead researcher. STATA was employed for actual data analysis; simple descriptive statistics were employed in characterizing the respondents. Logistic regression analyses were employed in predicting the influence of some key socio-demographic variables on the type of challenges family caregivers face. Qualitative data consisted of textual data, mainly transcripts from In-depth interviews. All interviews were tape recorded and detailed notes were taken simultaneously, including verbal citations. Recorded interviews were manually transcribed, read and reread by the researchers and organized along thematic lines. Findings from the qualitative inquiry were used to complement and support findings from the quantitative data.

\subsection{Consent}

Verbal informed consent was obtained from all participants prior to study and interviews. Care was taken to ensure that their confidentiality was maintained.

\section{Results}

\subsection{Section 1: Sociodemographic Information of Respondents}

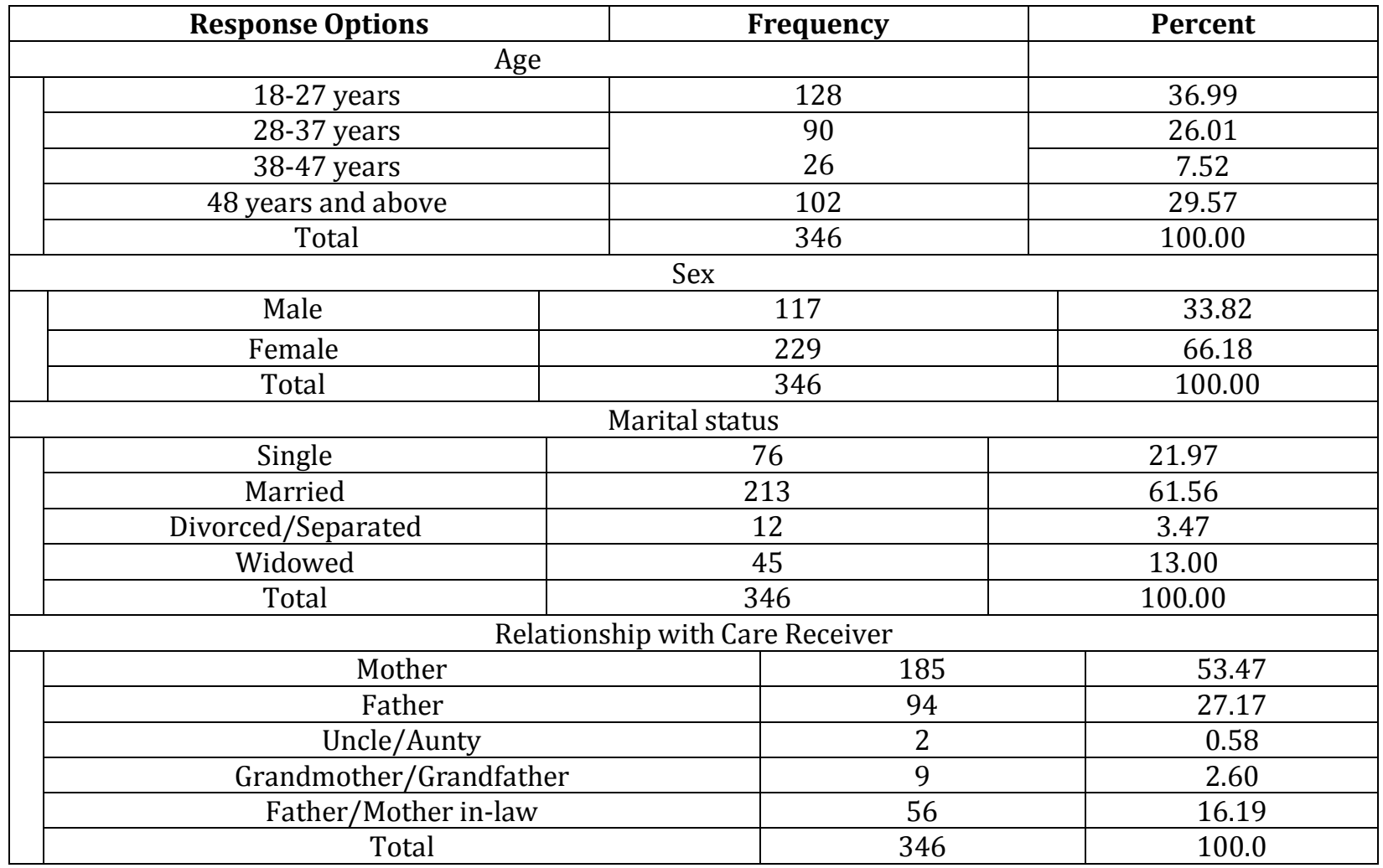

Table 1: Socio-Demographic Information of Respondents Source: Field Survey, 2018

The result on Table 1 showed the socio-demographic information of the sampled caregivers. As seen on the table, majority (36.99\%) were aged 18-27yrs while those aged 48 and above made up $29.57 \%$ of the respondents.26.01\% were aged $28-37 y r s$ and those aged $38-47$ made up $7.52 \%$ of the respondents. This indicates that most of the sampled family 
caregivers were aged below 40 years. Majority (66.18\%) of the respondents were female while $33.82 \%$ were males. This shows that most of the family caregivers as expected are females.

More so, data from Table 1 shows that majority (61.56\%) of the respondents are married while $21.97 \%$ are single. $13 \%$ were widowed and $3.47 \%$ were either divorced or separated. This showed that most of the sampled family caregivers were married as expected. Also, majority (53.47\%) of respondents indicated that the elderly care receiver was their mother while $27.17 \%$ indicated that they were giving care to their elderly father. The respondents that indicated that they were giving care to their mother/father in-law made up $16.19 \%$ of the sampled population, $2.60 \%$ indicated that they were giving care to their grandmother/father and $0.58 \%$ identified the care receiver as their uncle/aunty. This depicts that most of the sampled caregivers were as expected taking care of their mothers.

\subsection{Section 2: Psychosocial Challenges Facing Family Caregivers}

\begin{tabular}{|c|c|c|}
\hline Social Challenges Facing Caregivers & Mentioned (\%) & Not Mentioned (\%) \\
\hline Felt isolated from outside world & $225(65.03)$ & $121(34.97)$ \\
\hline No time to socialize with friends & $319(92.20)$ & $27(7.80)$ \\
\hline Friends can't come for visitations & $154(44.51)$ & $192(55.49)$ \\
\hline & & $224(64.74)$ \\
\hline Inability to communicate freely with friends & $122(35.26)$ & \\
\hline & & $156(45.09)$ \\
\hline
\end{tabular}

Table 2: Distribution of Respondents by the Social Challenges They

Face While Giving Care to the Elderly

Source: Field Survey, 2018

The social challenges family caregivers face is presented in Table 2. From the result, majority (92.20\%) indicated that they had no time to socialize with friends while $65.03 \%$ of the respondents mentioned that they felt isolated from outside world. Also, 54.91\% of the respondents mentioned that their movements were restricted because of caregiving. On the other hand, only $44.51 \%$ of the respondents mentioned that of their friends could not visit them because of caregiving. More so, only $35.51 \%$ of the respondents indicated that they could not communicate freely with their friends because of caregiving. From the Table 2a, it could be seen that the main social challenge family care givers face in Enugu urban were feeling isolated from outside world, not having time to socialize with friends and having restricted movement. This finding was highlighted in the qualitative data. A female caregiver had this to say about social challenges family caregivers face

Main challenge I face is, in the aspect of my social life, when others go out to spend some time with their friends she don't allow me to do same, she is always complaining that I am still a small boy so she knows the best for me, because I am her last child. Also in as much as she appreciates what I do for her, she is the type that complains a lot so I do everything within my power to see that she is satisfied and happy because she is suffering from high Blood pressure.so she talking a lot can aggravate issues.[Respondent: IDI; Female caregiver, Enugu East LGA].

Another respondent stated thus:

In terms of my health it does not have any effect, its only on my social life because you don't have time to do all that your mates do, just like my grandmother have issue with remembering things I always make sure she is with someone at home, so it does not really give me time to do other things. To hustle and make money is even problem you are always with her, because you don't know what will happen in ten minutes when you are not with her. [Respondent: IDI; Female caregiver, Enugu North LGA]

\begin{tabular}{|c|c|c|}
\hline Economic Challenges facing Caregivers & Mentioned (\%) & Not Mentioned (\%) \\
\hline Increased expenditure & $332(95.95)$ & $14(4.05)$ \\
\hline Cannot take up more work because of caregiving & $217(62.72)$ & $129(37.28)$ \\
\hline $\begin{array}{l}\text { Feel restricted from pursuing their desired occupation } \\
\text { because of caregiving }\end{array}$ & $326(94.22)$ & $20(5.78)$ \\
\hline Decrease in disposable income & $341(98.56)$ & $5(1.44)$ \\
\hline Decrease in investment expenditure & $302(87.28)$ & $44(12.72)$ \\
\hline
\end{tabular}

Table 3: Distribution of Respondents by Economic Challenges They Face While Giving Care to the Elderly Source: Field Survey, 2018

Table 3 shows economic challenges facing family caregivers in Enugu urban. As seen on the table, majority $(98.56 \%)$ of the respondents mentioned that care giving decreased their disposable income (income left after taxes for either consumption or savings), 95.95\% of the respondents mentioned that caregiving increased their expenditure. Also, $94.22 \%$ of the respondents mentioned that they felt restricted from pursuing their desired occupation because of 
caregiving. More so, $62.72 \%$ of the respondents mentioned that they could not take up more works because of caregiving. From the findings, it could be seen that the economic challenges facing family care givers in Enugu urban were increased expenditure, inability to take up more works, restriction from pursuing desired occupation, decreased disposal income and decreased investment expenditure. Respondents that participated in the in-depth interviews also laid emphasis on severe economic challenges they face. This respondent had this to say;

Financially, it affects me because since my mother was diagnosed of stroke which you know requires a lot of money. I and my husband have resorted in treating her with herbal medicine instead of using western medicine because herbal medicine works faster but it's quite expensive. I have spent all my savings, almost every salary I earn goes into her treatment. We don't even have any more money to buy land [Respondent: IDI; Female caregiver, Enugu North LGA]

Another Respondent stated thus:

Yes, to a very big extent it does. My siblings don't really send money like before, anymore. So, I do most of the spending and I teach in private school so the amount they pay us is very small amount of money. This has affected the way she receives her medical treatment; the doctor comes four times a week to run test on her and we adjusted this to just twice a week in order to accommodate the bills. [Respondent: IDI; Male caregiver; Enugu East LGA]

Another respondent buttressed thus:

Yes, my financial status plays a very big role in the way I care for her, in as much I am not the only one paying her bills, my elder brother is also helping. But I cannot even go for outside work, the extra money I should me making, I cannot do that because I have to spend a lot of time at home looking after my father.... [Respondent: IDI; Male care-giver, Enugu South LGA]

\begin{tabular}{|c|c|c|}
\hline Psychological Challenges Facing Caregivers & Mentioned (\%) & Not Mentioned (\%) \\
\hline Feels isolated & $109(31.50)$ & $237(68.50)$ \\
\hline Feels depressed & $128(36.99)$ & $218(63.01)$ \\
\hline Feels mentally tired & $179(51.73)$ & $167(48.27)$ \\
\hline Feels burnt out & $181(52.31)$ & $165(47.69)$ \\
\hline Feel anxious & $295(85.26)$ & $51(14.74)$ \\
\hline
\end{tabular}

Table 4: Distribution of Respondents by the Psychological Challenges They

Face While Giving Care to the Elderly Source: Field Survey, 2018

Data from Table 4 showed the psychological challenges facing family caregivers in Enugu urban. From the Table, it could be seen that majority (85.26\%) of the respondents mentioned that they felt anxious most of the time while $52.31 \%$ of the respondents mentioned that they felt burn out. $51.73 \%$ of the respondents mentioned that they felt mentally tired, only $36.99 \%$ of the respondents mentioned that they felt depressed due to caregiving. The least (31.50\%) mentioned psychological challenge was feelings of isolation. From the discussions, it could be seen that the psychological challenges facing family caregivers in Enugu urban were feeling mentally tired, feeling burnt out and feeling anxious. Information from the qualitative data also highlighted the psychological trauma some family caregivers go through;

I really don't want to complain too much but if I must say the truth 'I am tired, mentally and otherwise'. Nothing you do for her (mother in-law) is good, she is always complaining of pain here and there. She also complains when I try to make her eat, take a bath or her medication. At times she even starts crying over nothing. I don't know how long I can continue; I am almost getting depressed. At times I find myself crying too because of all the stress [Respondent: IDI; Female Caregiver, Enugu South LGA].

Another respondent also narrated her ordeal;

Nobody knows what I am going through. It is a very difficult thing. I have been taking care of my aged mother for eight years now and I can tell you without doubting that 'I am burnt out'. The stress is killing me. I have been begging my younger sister to take her for at least one month so that I can rest. The stress is already affecting my behavior towards my immediate family. I am anxious, sad and angry all the time, my husband and children are even complaining [Respondent: IDI; Female Caregiver, Enugu North LGA]

Data from Table 2, 3 and 4 showed that the social, economic and psychological challenges facing family care givers in Enugu urban were 'feeling isolated from outside world, not having time to socialize with friends, having restricted movement, increased expenditure, inability to take up more works, restriction from pursuing desired occupation, decreased disposal income, decreased investment expenditure, feeling mentally tired, feeling burnt out and feeling anxious.

\section{Discussion and Conclusion}

The findings from this study showed that majority (63\%) of the family caregivers sampled for this study was aged 18-37yrs and over $66 \%$ of them were females. This finding is similar to findings in the study of Nortey et al (2017) in Ghana and Faronbi et al (2019) in Nigeria. This may be attributed to the fact that traditionally, caregiving in African and particularly in Nigeria has always been regarded as the duty of females. In Igbo societies, women have always occupied the traditional role of caregivers. It is their duty to care for children, husband, mother/father in-laws and the sick.

Findings in this study also revealed that family caregivers suffer several social, psychological and economic challenges in the care of the elderly. Studies have documented the psychological, social and financial consequences that 
befall family caregivers in their care of the elderly (Dohner, 2015; Lai, 2012; and Feinberg et al, 2011). This study found that family caregivers suffer several social challenges like feeling isolated from outside world, not having time to socialize, not being able to entertain visitors/friends, unable to communicate freely with friends and restricted movement. Similarly, Bassah, Ubenoh and Palle (2018) in their exploratory study on knowledge and practices of Family caregivers in Cameroon, reported that family caregivers indicated that they had no time to pursue personal activities. In the same vein, Ebimgbo, Chukwu, Onalu and Okoye, (2019) also reported in their study of challenges associated with care of older adults by family caregivers in Southeast Nigeria that family caregivers reported that they lacked sufficient time for themselves.

Findings in this study also brought to light a number of psychological challenges family caregivers face in Enugu urban. Family caregivers in this study indicated that they felt isolated, depressed, mentally tired, burnt out and anxious while giving care to the elderly person. This psychological burden is not peculiar to family caregivers in Enugu urban. Similar studies in Nigeria (Ebimgbo et al, 2019; Ogunmodede et al, 2019) and Morocco (Lkhoyaali, et al, 2015) found that family caregivers underwent tremendous stress, psychological distress, depression and extreme anxieties while giving care to the elderly.

Findings from this study further revealed that family caregivers are overwhelmed with financial and economic consequences of giving care to the elderly. Family caregivers in this study pointed out that they are experiencing increased expenditure, cannot take up more work, are restricted from pursuing desired occupations, decrease in disposable income and decrease in investment expenditure as a result of caregiving. The qualitative data showed that family caregivers found themselves incapable of securing a stable financial future, even when finances is supplemented by significant others or relatives, they still felt the financial and economic burdens in other forms. Studies on the burden of caregiving on family caregivers have reported similar findings from their studies. For instance, Faronbi et al (2019) reported that family caregivers claimed that their businesses suffered because of neglect due to the caregiving process and those working in formal sectors received queries as a result of absenteeism. Ebimgbo, et al (2019) reported that family caregivers in their study lamented that care of the elderly has depleted their resources to the barest minimum and are constantly in need of finances to continue care. Other studies in Ghana and Cameroon (Nortey, et al, 2017 and Bassah, Ubenoh \& Palle, 2018) also reported that majority of family caregivers in their study indicated that their finances have gotten worse as a result of caregiving for their elderly relative and needed financial assistance to enable them continue with their caregiving roles.

The study has shown that caregiving is a traditional role that most times cannot be avoided by family members in Enugu urban and family caregivers continue to face social, psychological and financial challenges. These challenges are back breaking for most family caregivers and threaten continued care of the elderly and wellbeing of these caregivers and their families. It is therefore recommended that Enugu State government provide a comprehensive social policy that incorporates social services as well as economic incentives for the care of the elderly. Social work activities should also take into consideration the plight and needs of the family caregivers by providing them with education and psychosocial support to adequately accomplish their caregiving roles to their elderly family members.

\section{References}

i. American Psychological Association (APA) (2014). Older Adults Health and Age-Related Change. Retrieved fromhttp://www.apa.org/pi/aging/resources/guides/older.aspx?item=6Accessed May 05, 2020.

ii. Bassah, N., Ubenoh, U.S. \& Palle, J.N (2018) An Exploratory Study of the Knowledge and Practices of Family Caregivers in the Care of the Elderly at Home in the Buea Health District, Cameroon. Journal of Gerontology and Geriatric Research. 7(3), 1-5

iii. Blake, A. (2017). Falls by Elderly People at Home: Prevalence and associated factors, Age Ageing17. 365-372.

iv. Bretherton, I. (1985) Attachment Theory: retrospect and prospect. Monographs of the Society for Research in Child Development. 50(1-2, serial No. 209)

v. Bowlby, J. (1988) Attachment and Loss. No 3. Random House

vi. Bowlby, J. (1982) Attachment and Loss: 1(2). New York Basic Book; 169/1982

vii. Chorn-Dunham, C., \& Dietz, B. E. (2003). If I'm not allowed to put my family first: Challenges experienced by women who are care-giving for family members with dementia. Journal of Women and Aging, 15(1), 55-70.

viii. Connidis, I. A. (2010). Family ties and ageing. LA: Pine Forge/Sage.

ix. Davis, L.L., Gilliss, C.L., and Harper, M.S. (2011). Family Care-giving: Implications for Rural Practice, Policy, Education, and Research. Rural Care-giving in the United States, 19-31.

x. Dohner, H. (2015) Family care of the older people in Europe: Summary of the Results of EUROFAMCARE. https://cordis.europa.eu/pub/life/docs/doehner.pdf.Access on June 25, 2020

xi. Ebimgbo, S.O., Chukwu, N.E., Onalu, C.E \& Okoye, U.O (2019) Perceived Challenges Associated with Care of Older Adults by Family Caregivers and Implications for Social Workers in Southeast Nigeria. Indian Journal of Gerontology. 33(2), 160-177

xii. Faronbi, J.O, Faronbi, G.0., Ayamolowo, S.J. \& Olaogun, A.A. (2019) Caring for the seniors with chronic illness: The lived experience of caregivers of older adults. Archives of Gerontology and Geriatrics. 82 (2019) 8-14

xiii. Feinberg, L., Reinhard, S., Houser, A., \& Choula, R. (2011) Valuing the Invaluable: 2011 Update. The Growing Contributions and Cost of Family Caregiving. AARP Public Policy. 51:1-8

xiv. Friedland, R. \& Lewis, S. (2004). Choosing a long-term care insurance policy: Understanding and improving the process. Center on an Aging Society Health Policy Institute. Georgetown University

xv. Gupta R, Rowe N, Pillai, V. (2009). Perceived caregiver burden in India: Implications for social services. Journal of Women and Social Work, 24. 69-81.

xvi. Help Age International (2001). Elder abuse in the healthcare services in Kenya. Kenya. 
xvii. Lai, D.W.L. (2012) Effects of Financial Cost on Caregiving Burden of Family Caregivers of Older

a. Adults. Sage Open. 2(4)

xviii. Lkhoyaali, S., Haj, M.A.E., Omrani, F.E., Layachi, M., Ismaili, N., Mrabti, H. \& Errihani, H. (2015) The burden among family caregivers of elderly cancer patients: Prospective study in a Moroccan population. BMC Research Notes, 8,347. https://doi.org/10.1186/s13104-015-1307-5

xix. McDaniel, S.H \& Pisani, A.R. (2012) Family Dynamics and Caregiving for People with Disabilities. In R.C Talley \& J.E. Crews (Eds), Caregiving: Research, Practice, Policy. Multiple Dimensions of Caregiving and Disabilities: Research, Practice, Policy 11-28. Springer Science. https://doi.org/10.1007/978-1-4614-3384-2_2

xx. Mikulincer, M., \& Shaver, P.R. (2007a). Boosting attachment security to promote mental health, pro-social values, and inter-group tolerance. Psychological Inquiry, 18.139-156.

xxi. National Alliance for Care-giving. (2010). Care for the Family Caregiver: A place to start. The White House Conference on Aging, Emblem-health.

xxii. Nortey, S.T., Aryeetey, G.C., Aikins, M., Amendah, D. \& Nonvignon, J (2017) Economic Burden of Family Caregiving for Elderly Population in Southern Ghana: The case of a periurban district. International Journal of Equity in Health. 16, 16(2017). http://doi.org/10.1186/s12939-016-0511-9

xxiii. Ogunmodede, A.J., Abiodun, O., Makanjuola, A.B., Olarinoye, K.J., Ogunmodede, J.A. \& Buhari, O.I. (2019) Burden of care and psychological distress in primary caregivers of patients with Type-2 Diabetes Mellitus in a tertiary hospital in Nigeria. Ethiopian Journal of Health Science. 29(6),697-708

xxiv. Ogwumike, F. O. \& Aboderin, I. (2005). Exploring the links between old age and poverty in Anglophone West Africa: Evidence from Nigeria and Ghana. Generations Review, 15 (2). 7 - 15.

xxv. Okoye, U. O. (2012), 'Family care-giving for ageing parents in Nigeria: gender differences, cultural imperatives and the role of education'. International Journal of Education and Ageing,2(2), 139-154.

xxvi. United Nations. (2015). World Population Prospects: The 2015 Revision. New York: United Nations.https://esa.un.org/unpd/wpp/publications/files/key_findings_wpp_2015.pdfAccessed May 102020

xxvii. World Health Organization. (2011). Global Health and Ageing.

www.nia.nih.gov/sites/default/files/global_health_and_aging.pdf._Accessed May 10, 2020 